\title{
Tolerance Response to Iron Chlorosis of Prunus Selections as Rootstocks
}

\author{
Sergio Jiménez ${ }^{1}$ \\ Departamento de Pomología, Estación Experimental de Aula Dei (CSIC), \\ E-50080 Zaragoza, Spain
}

Jorge Pinochet

Agromillora Catalana S.A., El Rebato s/n, E-08739 T.M. Subirats, Barcelona, Spain

\section{Anunciación Abadía}

Departamento de Nutrición Veget, Estación Experimental de Aula Dei (CSIC), E-50080 Zaragoza, Spain

\section{María Ángeles Moreno and Yolanda Gogorcena ${ }^{2}$ \\ Departamento de Pomología, Estación Experimental de Aula Dei (CSIC), E-50080 Zaragoza, Spain}

Additional index words. Ferric chelate reductase, hydroponics, SPAD

\begin{abstract}
The use of rootstocks tolerant to iron deficiency represents the best alternative to prevent $\mathrm{Fe}$ chlorosis for peach production in calcareous soils. Early detection laboratory screening procedures allow the selection of new Fe-efficient rootstock genotypes. Seventeen Prunus rootstocks were tested for root ferric chelate reductase (FC-R) enzymatic activity, leaf SPAD values, and field performance. Some rootstocks were used as a reference to compare with new Prunus selections. Micropropagated plants were grown in hydroponic culture with half-strength Hoagland's nutrient solution containing $90 \mu \mathrm{Me}(\mathrm{III})$-EDTA as a control treatment. Plants were transferred to iron-free fresh solutions for 4 days and were thereafter resupplied with $180 \mu \mathrm{M} F \mathrm{Fe}$ (III)-EDTA for 1 or 2 days. In vivo FC-R activity was measured in all treatments, i.e., control, Fe-deficient, and $180 \mu \mathrm{M}$ Fe(III)-EDTA resupplied plants. The FC-R activity after Fe resupply was higher in Fe-efficient genotypes such as Adesoto ${ }^{\mathrm{PVP}}$, Felinem ${ }^{\mathrm{PVP}}$, GF 677, Krymsk 86 $^{\mathrm{TM}}$, and PAC 9921-07 than in the controls. No induction of FC-R activity was found in other genotypes such as Barrier, Cadaman ${ }^{\mathrm{TM}}$-Avimag ${ }^{\mathrm{PVP}}$, PAC 9907-23, and PAC 9908-02. An intermediate response was observed in Garnem ${ }^{\mathrm{PVP}}$, Gisela $5^{\mathrm{PVP}}$, Krymsk $1^{\mathrm{PVP}}$, Torinel ${ }^{\mathrm{TM}}$ Avifel $^{\mathrm{PVP}}$, VSL-2 ${ }^{\mathrm{TM}}$, and PAC 9904-01. According to the induction of FC-R activity after Fe resupply, genotypes were classified as tolerant, moderately tolerant, or nontolerant to iron-induced chlorosis. These results were compared with SPAD values of plants grown under controlled conditions and in the nursery. Rootstocks that show high induction of FC-R activity also showed high or very high SPAD values in the field.
\end{abstract}

Iron is an essential micronutrient for plant growth and development because of its importance in numerous cellular functions. Low iron bioavailability is mainly the result of its

\footnotetext{
Received for publication 12 July 2007. Accepted for publication 15 Oct. 2007.

Financial support was provided by Interministerial Commission of Science and Technology (nos. AGL2002-04219, AGL2003-01999, and AGL200505533), PETRI (no. PTR1995-0580), and DGA (nos. A28 and A44), and was cofunded by the European Regional Development Fund. S. Jiménez was supported by an I3P fellowship from CSIC/ FSE (Spanish Council for Scientific Research/ European Social Fund).

We gratefully acknowledge M. Cunill, P. Sánchez, and A. Santos for plant material management, and T. Zaharieva and G. Reighard for critical reading of this manuscript.

${ }^{1}$ Current address: Department of Horticulture, E-143 Poole Agriculture Center, Clemson University, Clemson SC 29634-0319.

${ }^{2}$ To whom reprint requests should be addressed; e-mail aoiz@eead.csic.es
}

insolubility at higher $\mathrm{pH}$ values, especially in calcareous soils, where roots are unable to acquire Fe (Hell and Stephan, 2003).

Lime-induced Fe deficiency has a strong effect in the production of several fruit crops of high economic importance grown in calcareous soils. Iron chlorosis is a common problem in peach, pear, quince, kiwi, and citrus (Tagliavini and Rombolà, 2001), is known to reduce fruit yield and quality, and to affect tree growth (Almaliotis et al., 1995). In addition, it delays fruit ripening (ÁlvarezFernández et al., 2003) and increases orchard management costs (Abadía et al., 2004; Sanz et al., 1992).

The use of Fe chlorosis-tolerant genotypes as rootstocks represents a reliable solution to prevent iron chlorosis (Socias i Company et al., 1995; Tagliavini and Rombolà, 2001). The GF 677 rootstock has a high tolerance to iron chlorosis (Cinelli et al., 2004; Giorgi et al., 2005; Socias i Company et al., 1995). Despite it being widely present throughout Europe, GF 677 is becoming obsolete because of its susceptibility to Agrobacterium tumefaciens and root-knot nematodes (Fernández et al., 1994), and excess vigor (Tagliavini and Rombolà, 2001), nonsuitable in the present production systems (DeJong et al., 1999). Subsequently, it is necessary to find and test new tolerant genotypes to lime-induced chlorosis, which must fulfill other agronomic requirements such as compatibility with the grafted cultivar and tolerance or resistance to soil-borne pests and diseases (Reighard et al., 2006) to use them as commercial rootstocks. Traditional selection procedures used to detect tolerance to iron chlorosis are based on field evaluation (Socias i Company et al., 1995). However, this practice requires long evaluation periods, is time consuming, and is very expensive. Therefore, rootstock breeding programs should benefit from new evaluation methods that would enable early detection of iron chlorosis. Laboratory methods based on plant physiological responses to chlorosis can be used for early selection of tolerant plant genotypes (Jolley et al., 1996) that must be confirmed later in field conditions. Several studies to select new genotypes tolerant to iron chlorosis in woody plants have been based on the root capacity to reduce $\mathrm{Fe}$ chelates (Dell'Orto et al., 2000; Gogorcena et al., 2000, 2004; Marino et al., 2000; Romera et al., 1991b), the chlorophyll content of leaves (Cinelli and Loreti, 2004; De la Guardia and Alcántara, 2002), or the root organic acid content (Jiménez et al., 2007; Ollat et al., 2003).

Two mechanisms have been described to acquire Fe from the growth medium under iron deficiency: one in dicots and nongraminaceous monocots called Strategy I and another one in graminaceous monocots called Strategy II. In general, Strategy I plants show morphological and cytological changes in the roots, e.g., swelling of the root tips, and formation of root hairs and transfer cells in the root epidermis. Possible physiological changes of this mechanism include acidification of the rhizosphere, exudation of reducing and chelating substances, and increase in ferric chelate reductase (FC-R) activity (reviewed in Schmidt, 1999), which reduces $\mathrm{Fe}^{3+}$ and enables uptake via an Fe transporter (Briat and Lobréaux, 1997). The FC-R increases the $\mathrm{Fe}^{2+}$ concentration at the cell surface for uptake by the roots (Moog and Brüggemann, 1994). Unlike graminaceous monocots, reduction of $\mathrm{Fe}^{3+}$ to $\mathrm{Fe}^{2+}$ is obligatory for absorption in Strategy I plants (Chaney et al., 1972; Yi and Guerinot, 1996). In iron-efficient plants, these induced iron deficiency responses are obviously enhanced under iron shortage (Bienfait et al., 1983; Fox et al., 1996).

The aim of this study was to evaluate the Fe-deficiency induction of in vivo root FC-Ractivity in 17 commercial and experimental Prunus rootstocks. The results obtained with the screening protocol were compared with leaf SPAD readings obtained under field conditions that induced iron chlorosis. 


\section{Materials and Methods}

Plant material and growth conditions. The plant material used in this investigation belonged to the breeding programs of Agromillora Catalana S.A. (Barcelona, Spain), the Estación Experimental de Aula Dei (Zaragoza, Spain), and others. (Adesoto $^{\mathrm{PVP}}$, Barrier, Cadaman ${ }^{\mathrm{TM}}$-Avimag $^{\mathrm{PVP}}$, Felinem $^{\text {PVP }}$, Garnem ${ }^{\text {PVP }}$, GF 677, Gisela $5^{\text {PVP, }}$, Krymsk $1^{\mathrm{PVP}}$, Krymsk $86^{\mathrm{TM}}$, Torinel ${ }^{\mathrm{TM}}$ Avifel $^{\mathrm{PVP}}$, VSL-2 ${ }^{\mathrm{TM}}$, PAC 9904-01, PAC 9907-02, PAC 9907-23, PAC 9908-02, PAC 9921-07, and PAC 0006-05) were obtained from Agromillora Catalana S.A. (Barcelona, Spain). The origin and species composition of these rootstocks are listed in Table 1 . Plants were grown for 2 weeks in $300-\mathrm{cm}^{3}$ pots containing a peat substrate. Thirty-four plants of each genotype were then transferred to 10 -L plastic containers filled with halfstrength Hoagland's nutrient solution. The nutrient solution was composed of $2.5 \mathrm{~mm}$ $\mathrm{Ca}\left(\mathrm{NO}_{3}\right)_{2}, 2.5 \mathrm{~mm} \mathrm{KNO}_{3}, 1 \mathrm{~mm} \mathrm{MgSO} \mathrm{Mg}_{4}, 1 \mathrm{~mm}$ $\mathrm{KH}_{2} \mathrm{PO}_{4}, 46.2 \mu \mathrm{M} \mathrm{H}_{3} \mathrm{BO}_{3}, 9.2 \mu \mathrm{M} \mathrm{MnCl}_{2}$, $0.38 \mu \mathrm{M} \mathrm{CuSO}_{4}, 2.4 \mu \mathrm{M} \mathrm{ZnSO}_{4}, 0.12 \mu \mathrm{M}$ $\mathrm{Na}_{2} \mathrm{MoO}_{4}(\mathrm{pH}$ 6.0), and $90 \mu \mathrm{M}$ Fe(III)EDTA. Plants were grown in a continuously aerated nutrient solution in a growth chamber under controlled environmental conditions, with a 16 -h photoperiod $\left(220 \mu \mathrm{mol} \mathrm{m} \mathrm{m}^{-2} \mathrm{~s}^{-1}\right)$ at $23{ }^{\circ} \mathrm{C}$ and $8 \mathrm{~h}$ of darkness at $20^{\circ} \mathrm{C}$ with the relative humidity maintained at $70 \%$ to $75 \%$. The nutrient solution was changed every 4 days, and the $\mathrm{pH}$ was checked and readjusted to 6.0 if necessary every 2 days, unless otherwise stated.

After stems and roots were about 15 and $10 \mathrm{~cm}$ long, respectively, plants were submitted to two treatments: 18 plants were transferred to iron-free solution $(-\mathrm{Fe})$ and six were kept in solution containing $90 \mu \mathrm{M}$ $\mathrm{Fe}(\mathrm{III})$-EDTA (+Fe). After 4 days, $12(-\mathrm{Fe})$ plants were resupplied with $180 \mu \mathrm{M} \mathrm{Fe}(\mathrm{III})-$
Micropropagated Prunus rootstocks

EDTA for 1 (180-1d) or 2 (180-2d) days. There were four different nutrient solution treatments for each genotype, namely: deficient $(-\mathrm{Fe})$ (5 days without iron), control $(+\mathrm{Fe})$, and resupply (180-1d) and (180-2d).

On the other hand, 20 plants of each genotype were planted in the nursery of the Estación Experimental de Aula Dei. Plants were grown on calcareous soil having $29 \%$ to $31 \%$ total calcium carbonate, $8.1 \%$ to $9.9 \%$ active lime, $\mathrm{pH}$ 9.0, and a silt-loam texture.

Measurement of in vivo root reduction with whole plants. In vivo root $\mathrm{FC}-\mathrm{R}$ activity of intact plants was carried out in the growth chamber. Plant roots were rinsed in deionized water, and individual plants were transferred to $50-\mathrm{mL}$ black plastic beakers covered with tape to exclude light and containing $49 \mathrm{~mL}$ of $300 \mu \mathrm{M}$ bathophenanthrolinedisulfonic acid (BPDS; ACROS Organics, Geel, Belgium) and $10 \mathrm{~mm}$ MES, $\mathrm{pH}$ 6.0, continuously aerated. One milliliter of $\mathrm{Fe}(\mathrm{III})$-EDTA (Sigma, St. Louis) was added to a final concentration of $500 \mu \mathrm{M}$. After one hour, $1-\mathrm{mL}$ aliquots were taken and centrifuged to exclude any solid particles. Reduction rates of $\mathrm{Fe}$ (III) were estimated spectrophotometrically from the formation of the Fe(II)-BPDS colored complex at $535 \mathrm{~nm}$ and an extinction coefficient of $22.14 \mathrm{~mm}^{-1} \cdot \mathrm{cm}^{-1}$ (Bienfait et al., 1983; Chaney et al., 1972; Cinelli et al., 1995; Gogorcena et al., 2000) after subtraction of blanks. Blank solutions were estimated without plants. At least five plants were used as replicates for each treatment.

SPAD measurements. The iron chlorosis level was assessed with a SPAD-502 Chlorophyll Meter [Minolta Camera Co. (no longer in business as a camera company)] in ungrafted plants grown in the climatic chamber and in the field. The second, fully expanded leaf was used for the SPAD measurement in plants grown in the chamber. Values of the $2 \mathrm{~d}$ of resupply were averaged (180).

Table 1. Rootstocks species and origin.

\begin{tabular}{|c|c|c|}
\hline Rootstock $^{\mathrm{z}}$ & Species & Origin $^{y}$ \\
\hline$\overline{\text { Adesoto }}^{\text {PVP }}$ & $P$. insititia & CSIC, Spain \\
\hline Barrier & $P$. persica $\times P$. davidiana & CNR, Italy \\
\hline Cadaman $^{\mathrm{TM}}$-Avimag ${ }^{\mathrm{PVP}}$ & $P$. persica $\times P$. davidiana & INRA, France and Hungary \\
\hline Felinem $^{\text {PVP }}$ & $P$. dulcis $\times P$. persica & CITA, Spain \\
\hline Garnem $^{\mathrm{PVP}}$ & P. dulcis $\times P$. persica & CITA, Spain \\
\hline GF 677 & $P$. dulcis $\times P$. persica & INRA, France \\
\hline Gisela $5^{\mathrm{PVP}}$ & $P$. canescens $\times P$. cerasus & UG, Germany \\
\hline Krymsk $1^{\text {PVP }}$ (VVA-1) & $P$. cerasifera $\times P$. tomentosa & KEBS, Russia \\
\hline Krymsk $86^{\mathrm{TM}}$ & $P$. cerasifera $\times P$. persica & KEBS, Russia \\
\hline Torinel $^{\mathrm{TM}}$-Avifel ${ }^{\mathrm{PVP}}$ & $P$. domestica $\times P$. spinosa & INRA, France \\
\hline VSL-2 $2^{\mathrm{TM}}$ & $P$. fruticosa $\times P$. lannesiana & KEBS, Russia \\
\hline PAC 9904-01 & $\begin{array}{l}(P . \text { davidiana } \times P \text {. persica }) \times \\
\quad(P . \text { dulcis } \times P \text {. persica })\end{array}$ & AC, Spain \\
\hline PAC 9907-02 & $P$. dulcis $\times(P$. persica $\times P$. persica $)$ & AC, Spain \\
\hline PAC 9907-23 & $(P$. dulcis $\times P$. persica $) \times P$. persica & AC, Spain \\
\hline PAC 9908-02 & $(P$. dulcis $\times P$. persica $) \times P$. persica & AC, Spain \\
\hline PAC 9921-07 & $(P$. besseyi $\times P$. salicina $) \times P$. armeniaca & AC, Spain \\
\hline PAC 0006-05 & $(P$. dulcis $\times P$. persica $) \times P$. persica & AC, Spain \\
\hline
\end{tabular}

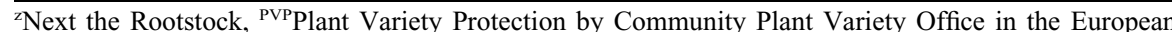
Union (2006), ${ }^{\text {TMTrademark. }}$

${ }^{y} \mathrm{AC}=$ Agromillora Catalana, S.A. private nursery, Spain; CITA = Centro de Investigación y Tecnología Agroalimentaria de Aragón; CNR = Centro Nacionale della Recerca; CSIC = Consejo Superior de Investigaciones Científicas; INRA = Institut National de la Recherche Agronomique; UG = University of Giessen; KEBS = Krymsk Experiment Breeding Station.
In 2003, SPAD values of plants established in the nursery of the Estación Experimental de Aula Dei were obtained in the months of July and August from 1-year-old ungrafted plants. Ten young fully expanded leaves from different areas of each plant were measured to obtain an average leaf SPAD value. At least five replicates were taken per rootstock.

Leaf mineral analysis. Leaf samples were collected from plants after measuring the FC-R activity of the different treatments. The leaves were subjected to three consecutive washings ( $\mathrm{HCl}$ diluted, soapy water, and deionized water) for removing elements adhered on their surface and afterward were dried in a forced air oven at $60{ }^{\circ} \mathrm{C}$ and ground up for mineral analysis.

The mineral elements of the dried samples were measured using the methods of C.I.I. (1969) and C.I.I. et al. (1975). Nitrogen was determined by Kjeldahl analysis; $\mathrm{P}$ was analyzed by ultraviolet spectrophotometry ( $8452 \mathrm{~A}$; Hewlett-Packard, Palo Alto, CA); K by atomic emission spectroscopy, and $\mathrm{Ca}, \mathrm{Mg}, \mathrm{Fe}, \mathrm{Mn}$, $\mathrm{Cu}, \mathrm{Na}$, and $\mathrm{Zn}$ by atomic absorption spectroscopy (1100; Perkin-Elmer, Norwalk, CT).

Data analysis. Data were evaluated by analysis of variance with SPSS 13.0.1 (SPSS, Chicago). When the F test was significant, means were separated by Duncan's multiple range test $(P \leq 0.05)$. Regression analysis was done between the FC-R activity ratio and the SPAD values of resupplied treatments under controlled conditions. The atypical data of the Krymsk $86^{\mathrm{TM}}$ mean ratio was not included in the Pearson's correlation analysis.

\section{Results and Discussion}

$F C-R$ activity. Seventeen commercial and experimental Prunus rootstocks were tested for their tolerance to $\mathrm{Fe}$ deficiency. For a better evaluation of the results, GF 677 rootstock was used as a reference rootstock. Increases in FC-R activity were not found in Fe-deficient Prunus plants compared with the control treatment (Fig. 1), but the complete lack and then the later addition of $\mathrm{Fe}$ may trigger increases in FC-R activity (Fig. 1; Gogorcena et al., 2004). The FC-R activity in control and resupplied plants varied widely among the evaluated genotypes (1-13 nmol $\mathrm{Fe}^{2+} \mathrm{min}^{-1} \cdot \mathrm{g}^{-1}$ fresh weight and $1-42 \mathrm{nmol}$ $\mathrm{Fe}^{2+} \min ^{-1} \cdot \mathrm{g}^{-1}$ fresh weight, respectively). To determine the induction capacity of the FC-R, the ratio between FC-R of plants resupplied with $180 \mu \mathrm{M}$ Fe(III)-EDTA during 1 or $2 \mathrm{~d}$ and the activity of control plants was calculated. According to maximum activity ratios, three groups of responses were established (Table 2): higher than 3.9, between 3.0 and 1.9 , and the third with no induction or induction lower than 1.8.

Some of the rootstocks, such as Adesoto $^{\mathrm{PVP}}$, Felinem ${ }^{\mathrm{PVP}}$, Krymsk $86^{\mathrm{TM}}$, and PAC 9921-07, showed higher FC-R activity after 1 or $2 \mathrm{~d}$ of Fe resupply than did GF 677 (Fig. 1A). Within this group, PAC 9921-07 rootstock showed the highest FC-R activity in the control and deficient treatments (7.6 and 


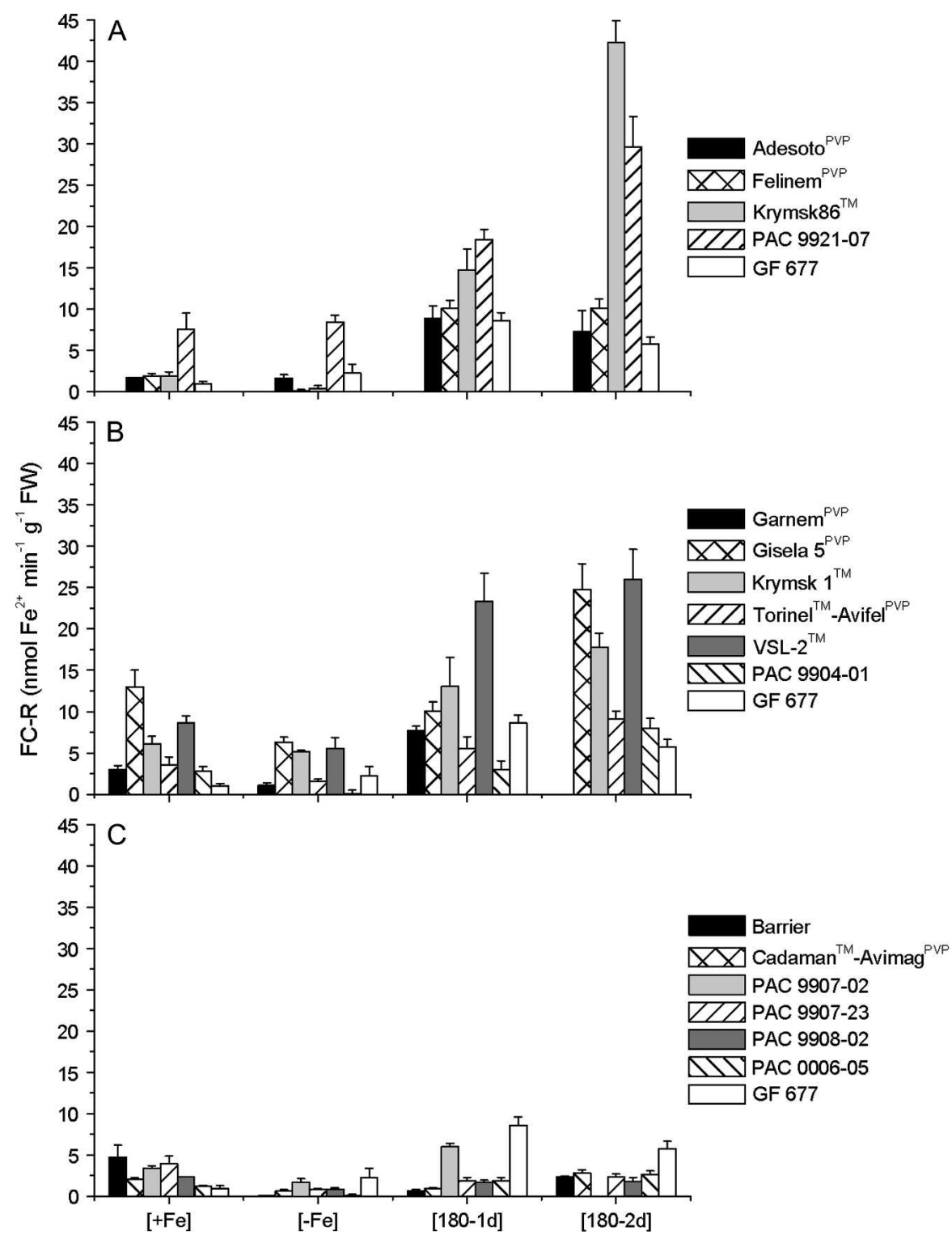

Fig. 1. Root FC-R activity (nmol Fe ${ }^{2+} \mathrm{min}^{-1} \cdot \mathrm{g}^{-1}$ fresh weight) of Adesoto ${ }^{\mathrm{PVP}}$, Felinem ${ }^{\mathrm{PVP}}$, Krymsk $86^{\mathrm{TM}}$, PAC 9921-07, and GF 677 (A); Garnem ${ }^{\mathrm{PVP}}$, Gisela $5^{\mathrm{PVP}}$, Krymsk $1^{\mathrm{PVP}}$, Torinel ${ }^{\mathrm{TM}}-$ Avifel ${ }^{\mathrm{PVP}}$, VSL-2 ${ }^{\mathrm{TM}}$, PAC 9904-01, and GF 677 (B); and Barrier, Cadaman ${ }^{\mathrm{TM}}$-Avimag $^{\mathrm{PVP}}$, PAC 9907-02, PAC 9907-23, PAC 9908 02, PAC 0006-05, and GF 677 (C) plants submitted to different treatments: control with $90 \mu \mathrm{M}$ FeIIIEDTA $(+\mathrm{Fe}), 5$ days Fe deficient $(-\mathrm{Fe})$, and 4 days deficient plants resupplied with $180 \mu \mathrm{m}$ FeIII-EDTA during 1 and $2 \mathrm{~d},(180-1 \mathrm{~d})$ and (180-2d), respectively. The chlorosis-tolerant genotype GF 677 is included as reference. Vertical bars indicate SE. At least five plants were used for treatment and rootstock.

$8.5 \mathrm{nmol} \mathrm{Fe}{ }^{2+} \min ^{-1} \cdot \mathrm{g}^{-1}$ fresh weight, respectively). For all genotypes in Fig. 1A (Adesoto $^{\mathrm{PVP}}$, Felinem ${ }^{\mathrm{PVP}}$, Krymsk $86^{\mathrm{TM}}$, PAC 9921 07, and GF 677), FC-R activity increased more than 3.9-fold after Fe resupply compared with the deficient treatment (Table 2). Likewise, Krymsk $86^{\mathrm{TM}}$ showed the highest increase in FC-R activity 2 days after iron addition (180-2d) (22.1-fold). Some of these genotypes were already assessed for Fe deficiency tolerance in field and controlled conditions. The plum rootstock Adesoto ${ }^{\mathrm{PVP}}$ was classified as tolerant to $\mathrm{Fe}$ chlorosis in the field (Moreno et al., 1995) and was also found to have a high FC-R activity rate (Gogorcena et al., 2004; Romera et al., 1991a; Santos, 2002). The peach-almond hybrid Felinem ${ }^{\text {PVP }}$ was evaluated under field conditions with a high lime content and showed a similar response to GF 677 (Felipe et al., 1997), probably because of the influence of its chlorosistolerant almond pedigree.

The FC-R activity of resupply treatments of Garnem ${ }^{\text {PVP }}$, Gisela $5^{\text {PVP }}$, Krymsk $1^{\text {PVP }}$, Torinel $^{\mathrm{TM}}$-Avifel ${ }^{\mathrm{PVP}}$, VSL-2 ${ }^{\mathrm{TM}}$, and PAC $9904-$ 01 rootstocks was similar or greater than the GF 677 values (Fig. 1B), but the control FC-R activity was also greater, especially for Gisela $5^{\mathrm{PVP}}$, Krymsk $1^{\mathrm{PVP}}$, and VSL-2 ${ }^{\mathrm{TM}}$ (13.0, 6.1 and $8.6 \mathrm{nmol} \mathrm{Fe}{ }^{2+} \min ^{-1} \cdot \mathrm{g}^{-1}$ fresh weight, respectively). The rootstocks Garnem $^{\text {PVP }}$, Gisela $5^{\text {PVP }}$, Krymsk $1^{\text {PVP }}$, Torinel $^{\mathrm{TM}}-$ Avifel $^{\mathrm{PVP}}$, VSL-2 ${ }^{\mathrm{TM}}$, and PAC 9904-01 showed moderate increases of FC-R activity, with maximum values between 1.9 and 3.0 (Table 2). Thus, the genotypes of this group showed an intermediate response.
Table 2. Induction of root FC-R activity 1 and 2 $\mathrm{d}$ after Fe resupply. Ratios were calculated as activity in plants resupplied with $180 \mu \mathrm{M}$ Fe(III)-EDTA during 1 or 2 days per activity of control treatment with $90 \mu \mathrm{M} \mathrm{Fe}(\mathrm{III})$-EDTA [FC-R (180-1d) per FC-R (+Fe) and FC-R (180-2d) per FC-R (+Fe), respectively].

\begin{tabular}{|c|c|c|}
\hline Rootstock & $\begin{array}{c}\text { FC-R } \\
(180-1 \mathrm{~d}) \\
\text { per FC-R } \\
(+\mathrm{Fe})^{\mathrm{z}}\end{array}$ & $\begin{array}{c}\text { FC-R } \\
(180-2 d) \\
\text { per FC-R } \\
(+F e)^{z, y}\end{array}$ \\
\hline$\overline{\text { Adesoto }}^{\text {PVP }}$ & 5.3 & 4.4 \\
\hline Felinem $^{\mathrm{PVP}}$ & 5.3 & 5.3 \\
\hline Krymsk $86^{\mathrm{TM}}$ & 7.7 & 22.1 \\
\hline PAC 9921-07 & 2.4 & 3.9 \\
\hline GF 677 & 8.9 & 5.9 \\
\hline Garnem $^{\mathrm{PVP}}$ & 2.6 & nd \\
\hline Gisela $5^{\mathrm{PVP}}$ & $\mathrm{ni}$ & 1.9 \\
\hline Krymsk $1^{\text {PVP }}$ & 2.1 & 2.9 \\
\hline Torinel $^{\mathrm{TM}}$-Avifel ${ }^{\mathrm{PVP}}$ & 1.6 & 2.6 \\
\hline VSL-2 $2^{\mathrm{TM}}$ & 2.7 & 3.0 \\
\hline PAC 9904-01 & 1.1 & 2.9 \\
\hline PAC 0006-05 & 1.6 & 2.2 \\
\hline Barrier & $\mathrm{ni}$ & ni \\
\hline Cadaman $^{\mathrm{TM}}$-Avimag $^{\mathrm{PVP}}$ & $\mathrm{ni}$ & 1.4 \\
\hline PAC 9907-02 & 1.8 & nd \\
\hline PAC 9907-23 & $\mathrm{ni}$ & $\mathrm{ni}$ \\
\hline PAC 9908-02 & $\mathrm{ni}$ & $\mathrm{ni}$ \\
\hline
\end{tabular}

${ }^{z}$ ni: no induction.

${ }^{y}$ nd: not determined.

On the other hand, the FC-R activity of $\mathrm{Fe}$ resupply treatments of Barrier, Cadaman ${ }^{\mathrm{TM}}$ Avimag $^{\text {PVP }}$, PAC 9907-02, PAC 9907-23, PAC 9908-02, and PAC 0006-05 rootstocks was lower than that in GF 677 (Fig. 1C). These rootstocks showed little or no increase in FC-R activity when resupplied versus the $(+\mathrm{Fe})$ treatment (Table 2$)$. The slightly higher increase of FC-R activity of PAC 0006-05 rootstock was because of a low control FC-R activity (Fig. 1C). The results for Barrier and Cadaman $^{\mathrm{TM}}$-Avimag ${ }^{\mathrm{PVP}}$ agree with those obtained by Gogorcena et al. (2004) using the same technique. Evaluation of Barrier on calcareous soil showed lower tolerance to ${\text { chlorosis than } \text { Adesoto }^{\text {PVP }} \text {, Felinem }}^{\text {PVP }}$, and GF 677 (Iglesias et al., 2004). Also, a recent study by Molassiotis et al. (2006) reported a higher sensitivity to iron chlorosis of Cadaman $^{\mathrm{TM}}$-Avimag ${ }^{\mathrm{PVP}}$ than GF 677.

The method used in this study was based on the induction of chelate reduction capacity in Fe-deficient peach roots (Gogorcena et al., 2000). With this methodology, Fe-deficient rootstocks show a change in FC-R activity and the response can be measured (Gogorcena et al., 2004). Other investigations on dry bean in hydroponics showed that root iron reducing capacities were highly negatively correlated with visual chlorosis scores from field trials (Ellsworth et al., 1997) and provide a better screening ability than $\mathrm{H}^{+}$ion release (Ellsworth et al., 1998). Moreover, under the growing conditions of this work, rootstocks did not induce acidification of the medium with iron deficiency. A high reduction capacity will allow the plant to increase $\mathrm{Fe}$ uptake under soil conditions inducing $\mathrm{Fe}$ deficiency, as it occurs on calcareous, high $\mathrm{pH}$ soils. The genotypes showing higher or moderate reduction capacities will have better adaptability to calcareous soils. 
$S P A D$ values and leaf $F e$ concentration. In hydroponic culture, leaves of all rootstocks had lower SPAD values in the $(-\mathrm{Fe})$ than $(+\mathrm{Fe})$ treatments (Table 3$)$. After 2 days of $\mathrm{Fe}$ resupply, rootstocks achieved SPAD units similar to control values $[ \pm 10 \%$ of $(+\mathrm{Fe})]$, except for Garnem ${ }^{\mathrm{PVP}}$, PAC 9904-01, PAC 0006-05, Barrier, Cadaman ${ }^{\mathrm{TM}}-$ Avimag $^{\mathrm{PVP}}$, and PAC 9907-02. Results of leaf mineral content analysis after Fe resupply indicated that the rootstocks with high reduction capac- ity had higher Fe concentrations than control plants (Table 3 ). The concentration of Fe in the resupply (180) treatment was considerably higher than the control for Adesoto ${ }^{\mathrm{PVP}}$, Felinem $^{\text {PVP }}$, Krymsk 86 ${ }^{\mathrm{TM}}$, PAC 9921-07, GF 677, Torinel ${ }^{\mathrm{TM}}-$ Avifel $^{\mathrm{PVP}}$, and VSL-2 ${ }^{\mathrm{TM}}$. The SPAD values of genotypes PAC 9904-01 and PAC 0006-05 were not recovered, although the induction of the FC-R was moderate to low (Table 2). Genotypes that did not induce the FC-R activity reached a similar or lower

Table 3. SPAD values of the second fully expanded leaf from the apex of plants grown with $90 \mu \mathrm{M} F e($ III)EDTA (+Fe), without Fe for $5 \mathrm{~d}(-\mathrm{Fe})$ and $4 \mathrm{~d}$ without Fe and then resupplied with $180 \mu \mathrm{M}$ Fe(III)EDTA for 1 (180-1d) or $2 \mathrm{~d}(180-2 \mathrm{~d})$ [average of two days, (180)]. The recovery of SPAD values and leaf $\mathrm{Fe}$ concentration in deficient plants after resupply was indicated as: = plants after iron resupply reached similar values than control $( \pm 10 \%) ;<$ plants after resupply showed lower values than control; $>$ plants after resupply reached higher values than control. SPAD data are means \pm SE of five replicates.

\begin{tabular}{|c|c|c|c|c|c|}
\hline \multirow[b]{2}{*}{ Rootstock } & \multicolumn{3}{|c|}{ SPAD } & \multirow{2}{*}{$\begin{array}{c}\text { SPAD } \\
\text { Recovery }\end{array}$} & \multirow{2}{*}{$\begin{array}{c}\text { Fe concentration } \\
\text { Recovery }^{z}\end{array}$} \\
\hline & $(+\mathrm{Fe})$ & $(-\mathrm{Fe})$ & $(180)$ & & \\
\hline$\overline{\text { Adesoto }}^{\text {PVP }}$ & $24.1 \pm 0.7$ & $19.4 \pm 1.9$ & $25.2 \pm 0.8$ & $=$ & $>$ \\
\hline Felinem $^{\text {PVP }}$ & $25.2 \pm 0.8$ & $22.2 \pm 0.6$ & $24.9 \pm 0.9$ & $=$ & $>$ \\
\hline Krymsk $86^{\mathrm{TM}}$ & $20.0 \pm 1.7$ & $10.0 \pm 0.1$ & $20.5 \pm 1.3$ & $=$ & $>$ \\
\hline PAC 9921-07 & $24.8 \pm 2.0$ & $15.4 \pm 1.4$ & $23.5 \pm 0.9$ & $=$ & $>$ \\
\hline GF 677 & $27.1 \pm 0.7$ & $22.2 \pm 3.5$ & $26.1 \pm 0.9$ & $=$ & $>$ \\
\hline Garnem $^{\text {PVP }}$ & $23.1 \pm 0.9$ & $21.2 \pm 0.6$ & $19.7 \pm 1.1$ & $<$ & $<$ \\
\hline Gisela $5^{\text {PVP }}$ & $19.5 \pm 1.1$ & $16.5 \pm 0.8$ & $20.4 \pm 2.2$ & $=$ & $=$ \\
\hline Krymsk $1^{\mathrm{PVP}}$ & $18.0 \pm 1.4$ & $13.6 \pm 8.1$ & $16.9 \pm 3.6$ & $=$ & $=$ \\
\hline Torinel $^{\mathrm{TM}}$-Avifel ${ }^{\mathrm{PVP}}$ & $24.1 \pm 1.1$ & $22.5 \pm 0.7$ & $23.6 \pm 0.4$ & $=$ & $>$ \\
\hline VSL-2 $2^{\mathrm{TM}}$ & $19.7 \pm 2.3$ & $16.3 \pm 0.7$ & $20.5 \pm 1.6$ & $=$ & $>$ \\
\hline PAC 9904-01 & $17.5 \pm 1.0$ & $11.9 \pm 1.0$ & $15.0 \pm 0.6$ & $<$ & nd \\
\hline PAC 0006-05 & $17.6 \pm 1.9$ & $6.4 \pm 1.2$ & $10.1 \pm 1.2$ & $<$ & nd \\
\hline Barrier & $18.1 \pm 2.9$ & $9.2 \pm 0.5$ & $12.8 \pm 1.3$ & $<$ & $<$ \\
\hline Cadaman $^{\mathrm{TM}}$-Avimag ${ }^{\mathrm{PVP}}$ & $18.5 \pm 1.6$ & $13.4 \pm 1.8$ & $16.5 \pm 1.2$ & $<$ & $<$ \\
\hline PAC 9907-02 & $25.2 \pm 1.7$ & $11.8 \pm 2.3$ & $21.3 \pm 2.7$ & $<$ & $=$ \\
\hline PAC 9907-23 & $26.0 \pm 0.9$ & $22.3 \pm 0.4$ & $25.5 \pm 0.8$ & $=$ & $=$ \\
\hline PAC 9908-02 & $20.9 \pm 1.2$ & $17.0 \pm 1.3$ & $21.1 \pm 0.7$ & $=$ & $=$ \\
\hline
\end{tabular}

${ }^{\mathrm{z}}$ nd: not determined.

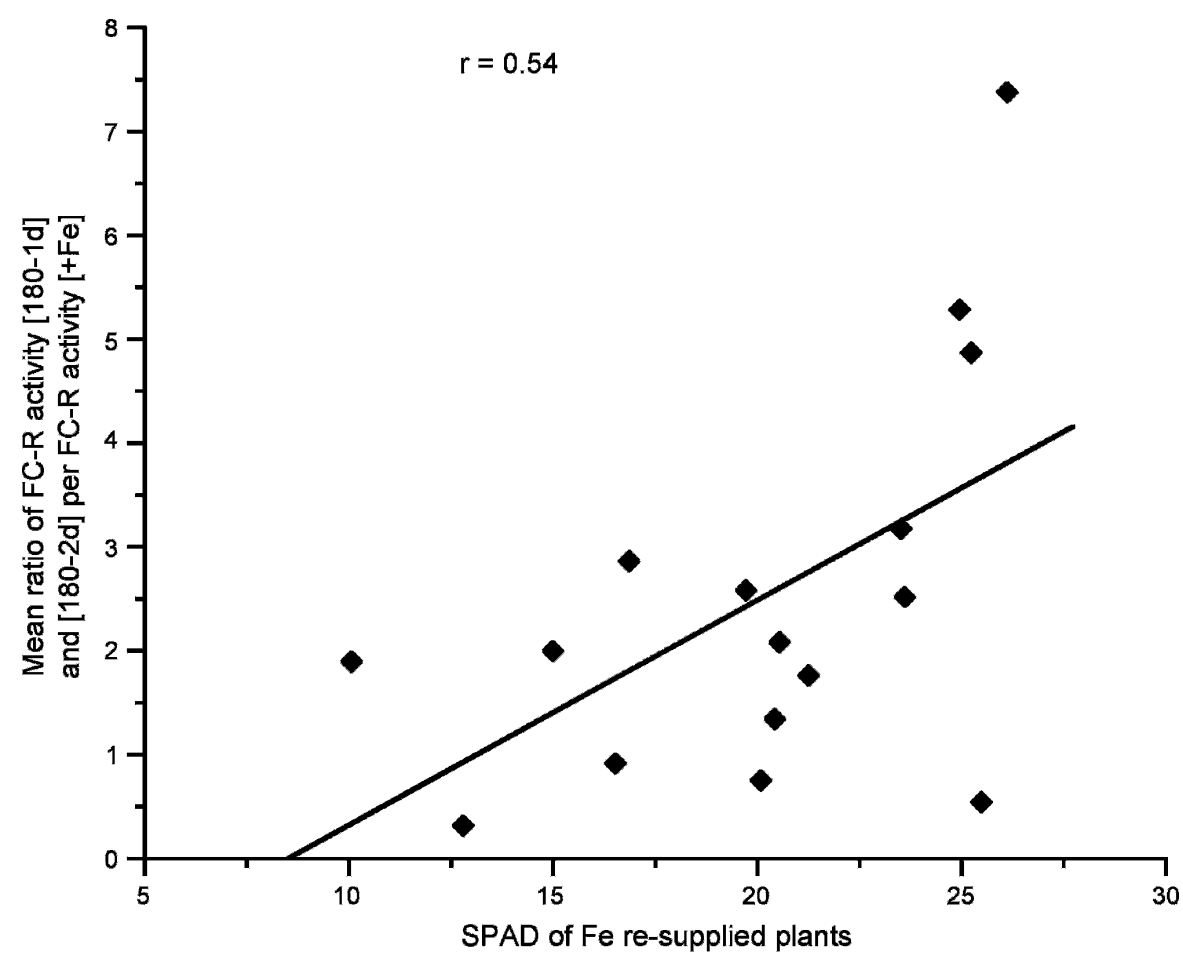

Fig. 2. Relationship between the mean ratio of FC-R activity of Adesoto ${ }^{\mathrm{PVP}}$, Barrier, Cadaman ${ }^{\mathrm{TM}}$ Avimag $^{\text {PVP }}$, Felinem ${ }^{\mathrm{PVP}}$, Garnem ${ }^{\mathrm{PVP}}$, GF 677, Gisela $5^{\mathrm{PVP}}$, Krymsk $1^{\mathrm{PVP}}$, Torinel ${ }^{\mathrm{TM}}$-Avifel $^{\mathrm{PVP}}$, VSL-2 ${ }^{\mathrm{TM}}$, PAC 9904-01, PAC 9907-02, PAC 9907-23, PAC 9908-02, PAC 9921-07, and PAC 0006-05 plants resupplied with $180 \mu \mathrm{M} \mathrm{Fe}$ (III)-EDTA during 1 (180-1d) and 2 (180-2d) days per FC-R activity of control plants $(+\mathrm{Fe})$ with $90 \mu \mathrm{M}$ Fe(III)-EDTA and SPAD values of the second fully expanded leaf from apex of deficient plants resupplied with $180 \mu \mathrm{M}$ Fe-EDTA. Linear relation with $P \leq 0.05$ is presented.

Fe concentration to that of control plants. However, the recovery in SPAD values and Fe concentration was similar to their respective control levels for the PAC 9907-23 and PAC 9908-02 genotypes. The increase in leaf iron concentrations of Adesoto ${ }^{\mathrm{PVP}}$ and GF 677 and the lower leaf iron concentration of Barrier and Cadaman ${ }^{\mathrm{TM}}$-Avimag ${ }^{\mathrm{PVP}}$ after Fe resupply was previously reported (Gogorcena et al., 2004; Santos, 2002). The rootstocks with high reduction capacity may increase the $\mathrm{Fe}^{2+}$ concentration at the cell surface for root uptake (Moog and Brüggemann, 1994) and the consequent translocation to the shoot, leading to high leaf $\mathrm{Fe}$ concentration. On the other hand, a significant positive correlation was found between the FC-R activity ratio of resupply per control treatment and SPAD values of resupplied plants (180) ( $P \leq 0.05$; Fig. 2). However, the high SPAD values for PAC 9907-23 caused a not high correlation coefficient. According to these data, it is likely that the stimulation of the FC-R activity was accompanied by decrease of symptoms of iron deficiency (higher SPAD values).

In the field, SPAD readings measured in ungrafted genotypes were very high for the genotypes with increased FC-R activities such as Adesoto ${ }^{\mathrm{PVP}}$, Krymsk $86^{\mathrm{TM}}$, and PAC 9921-07 (Table 4). Felinem ${ }^{\text {PVP }}$ and GF 677 had also high SPAD values, as observed by Felipe et al. (1997). Genotypes with intermediate FC-R activity responses showed intermediate SPAD values, although rootstocks such as Torinel ${ }^{\mathrm{TM}}$-Avifel ${ }^{\mathrm{PVP}}$ showed high SPAD readings. This could be caused by morphological genotype differences due to thickness and leaf chlorophyll density. In addition, leaf natural color of plum is darker than $P$. dulcis $\times P$. persica hybrids. Thus, variation between high and medium reduction capacities could not be fully explained. Conversely, rootstocks with a low reduction capacity showed SPAD readings in the field

Table 4. Leaf SPAD values of ungrafted rootstocks in nursery conditions that induce iron chlorosis. Data are means of at least five replicates.

\begin{tabular}{|c|c|}
\hline Rootstock & $\mathrm{SPAD}^{\mathrm{z}, \mathrm{s}}$ \\
\hline$\overline{\text { Adesoto }^{P V P}}$ & $47.7 \mathrm{f}$ \\
\hline Felinem $^{\text {PVP }}$ & $36.6 \mathrm{~cd}$ \\
\hline Krymsk $86^{\mathrm{TM}}$ & $41.5 \mathrm{e}$ \\
\hline PAC 9921-07 & $41.3 \mathrm{e}$ \\
\hline GF 677 & $35.8 \mathrm{~cd}$ \\
\hline Garnem $^{\text {PVP }}$ & $35.9 \mathrm{~cd}$ \\
\hline Gisela $5^{\mathrm{PVP}}$ & $37.1 \mathrm{~d}$ \\
\hline Krymsk $1^{\mathrm{PVP}}$ & $36.3 \mathrm{~cd}$ \\
\hline Torinel $^{\mathrm{TM}}$-Avifel ${ }^{\mathrm{PVP}}$ & $41.9 \mathrm{e}$ \\
\hline VSL-2 ${ }^{\mathrm{TM}}$ & $37.2 \mathrm{~d}$ \\
\hline PAC 9904-01 & $40.3 \mathrm{e}$ \\
\hline PAC 0006-05 & $\mathrm{nft}$ \\
\hline Barrier & $28.2 \mathrm{a}$ \\
\hline Cadaman $^{\mathrm{TM}}$-Avimag ${ }^{\mathrm{PVP}}$ & $33.7 \mathrm{bc}$ \\
\hline PAC 9907-02 & $31.6 \mathrm{~b}$ \\
\hline PAC 9907-23 & $\mathrm{nft}$ \\
\hline PAC 9908-02 & $\mathrm{nft}$ \\
\hline
\end{tabular}

${ }^{\mathrm{z}}$ Within column, means with the same letter do not differ significantly at $P \leq 0.05$ (Duncan's multiple range test).

${ }^{y}$ nft: not field tested. Not all genotypes evaluated under controlled conditions (hydroponic) were tested in the field. 


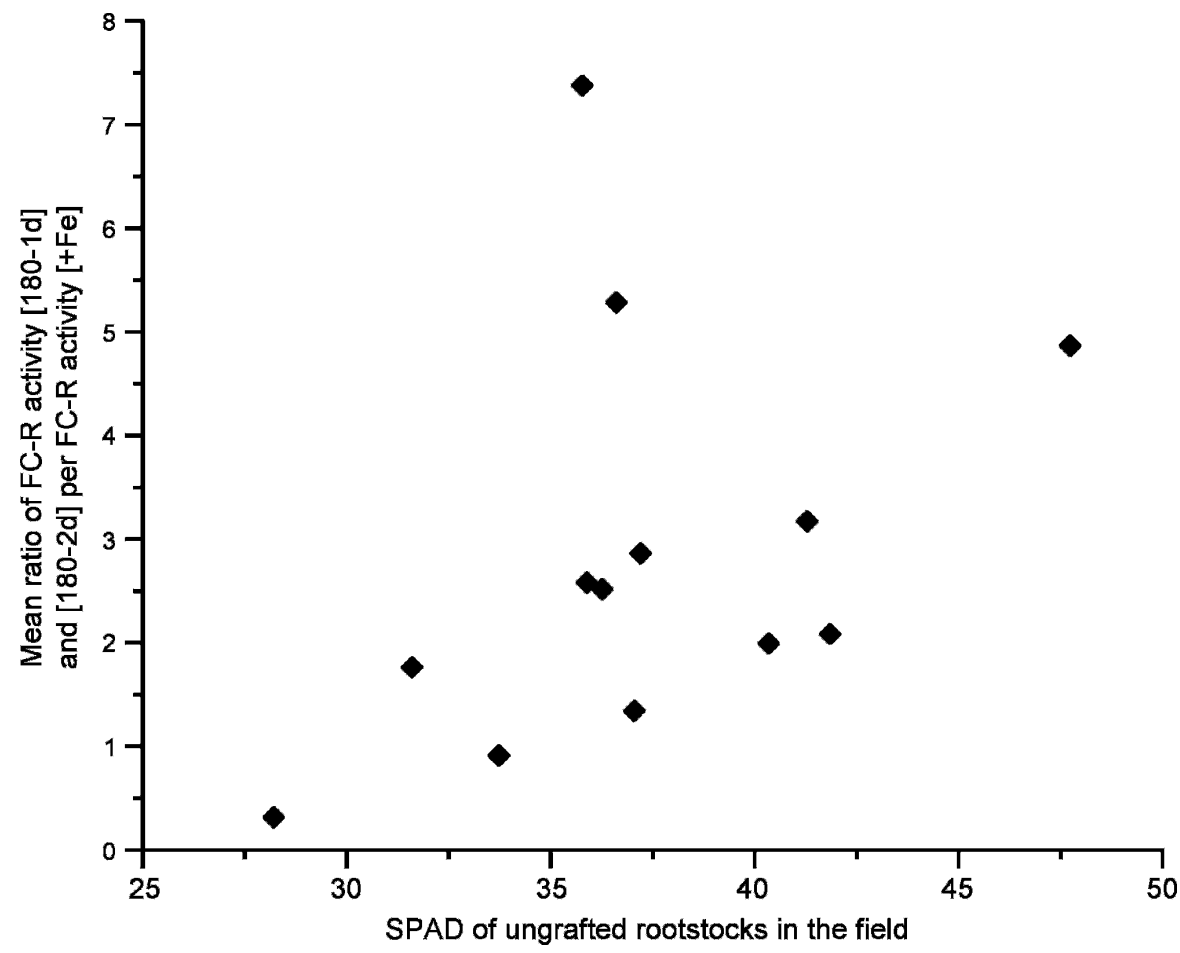

Fig. 3. Relationship between the mean ratio of FC-R activity of Adesoto ${ }^{\mathrm{PVP}}$, Barrier, Cadaman ${ }^{\mathrm{TM}}$ Avimag $^{\mathrm{PVP}}$, Felinem ${ }^{\mathrm{PVP}}$, Garnem ${ }^{\mathrm{PVP}}$, GF 677 , Gisela $5^{\mathrm{PVP}}$, Krymsk $1^{\mathrm{PVP}}$, Torinel $^{\mathrm{TM}}$-Avifel $^{\mathrm{PVP}}$, VSL$2^{\mathrm{TM}}$, PAC 9904-01, PAC 9907-02, PAC 9907-23, PAC 9908-02, PAC 9921-07, and PAC 0006-05 plants resupplied with $180 \mu \mathrm{M}$ Fe(III)-EDTA during 1 (180-1d) and 2 (180-2d) days per FC-R activity of control plants $(+\mathrm{Fe})$ with $90 \mu \mathrm{M} \mathrm{Fe}(\mathrm{III})$-EDTA and SPAD values of ungrafted rootstocks in nursery conditions that cause iron chlorosis.

below 33.7. The mean FC-R activity ratio of resupply treatments per control treatment and the field SPAD values were not significantly correlated (Fig. 3) mainly because of high FC-R activity response of Felinem ${ }^{\mathrm{PVP}}$ and GF 677.

The evaluation under controlled conditions could be extrapolated to predict the response of a rootstock in the field, although bearing in mind that $\mathrm{Fe}$ chlorosis could be influenced by other agronomic traits such as yield, vigor, and the rootstock-scion combination effect. In the nursery, the response of grafted rootstocks in terms of leaf chlorophyll content could be different with respect to the ungrafted rootstock. Further studies with grafted plants grown under control conditions (growth chamber) should be done to elucidate the influence of the cultivar on the rootstock response to iron chlorosis, although there are scion-stock compatibility requirements that prevented grafting all rootstocks with the same cultivar.

Relative chlorosis tolerance of 17 Prunus rootstocks. With the prevailing experimental conditions, one of the main responses of the Prunus roots to Fe deficiency was the variation in FC-R activity. According to FC-R activity increases, preliminary rating for several rootstocks is proposed for their tolerance to iron chlorosis: tolerant (Adesoto ${ }^{\mathrm{PVP}}$, Felinem $^{\text {PVP }}$, Krymsk 86 ${ }^{\mathrm{TM}}$, PAC 9921-07, and GF 677), moderately tolerant (Garnem ${ }^{\text {PVP }}$, Gisela $5^{\text {PVP }}$, Krymsk $1^{\text {PVP }}$, Torinel ${ }^{\mathrm{TM}}$ Avifel $^{\mathrm{PVP}}$, VSL-2 ${ }^{\mathrm{TM}}$, and PAC 9904-01), and sensitive (Barrier, Cadaman ${ }^{\mathrm{TM}}-$ Avimag $^{\mathrm{PVP}}$,
Technologies for the diagnosis and remediation of Fe deficiency. Soil Sci. Plant Nutr. 50:965971.

Almaliotis, D.D., A.G. Manganaris, A.D. Simonis, and S.B. Bladenopoulou. 1995. Rootstock effect on yield and mineral nutrition of 'Maycrest' peach trees under conditions of lime-induced chlorosis, p. 301-306. In: J. Abadía (ed.). Iron nutrition in soils and plants. Kluwer Academic Publishers, Dordrecht, The Netherlands.

Álvarez-Fernández, A., P. Paniagua, J. Abadía, and A. Abadía. 2003. Effects of Fe deficiency chlorosis on yield and fruit quality in peach (Prunus persica L. Batsch). J. Agr. Food Chem. 51:5738-5744.

Bienfait, H.F., R.J. Bino, A.M. Van Der Bliek, J.F. Duivenvoorden, and J.M. Fontaine. 1983. Characterization of ferric reducing activity in roots of Fe-deficient Phaseolus vulgaris. Physiol. Plant. 59:196-202.

Briat, J.F. and S. Lobréaux. 1997. Iron transport and storage in plants. Trends Plant Sci. 2:187193.

Chaney, R.L., J.C. Brown, and L.O. Tiffin. 1972. Obligatory reduction of ferric chelates in iron uptake by soybeans. Plant Physiol. 50:208213.

C.I.I. (Comité Inter-Institutos para el estudio de técnicas analíticas). 1969. Métodos de referencia para la determinación de elementos minerales en vegetales. An. Edafol. Agrobiol. 38:403-417

C.I.I. (Comité Inter-Institutes), M. Pinta and G. Dewaele. 1975. Etalons végétaux pour l'analyse foliaire, p. 159-172. In: In: P. Kozma (ed.). Le contrôle de l'alimentation des plantes cultivées. Akadémiai Kiadó, Budapest, Hungary.

Cinelli, F. and F. Loreti. 2004. Evaluation of some plum rootstocks in relation to lime-induced chlorosis by hydroponic culture. Acta Hort. 658:421-427.

Cinelli, F., I. Tamantini, and C. Iacona. 2004 Nutritional (Fe-Mn) interactions in 'Big Top' peach plants as influenced by the rootstock and by the soil $\mathrm{CaCO}_{3}$ concentration. Soil Sci. Plant Nutr. 50:1097-1102.

Cinelli, F., R. Viti, D.H. Byrne, and D.W. Reed. 1995. Physiological characterization of two peach seedling rootstocks in bicarbonate nutrient solution. I. Root iron reduction and iron uptake, p. 323-328. In: J. Abadía (ed.). Iron nutrition in soils and plants. Kluwer Academic Publishers, Dordrecht, The Netherlands.

Community Plant Variety Office in the European Union. 2006. Community Plant Variety Office in the European Union, Angers (France). $<$ http://www.cpvo.eu.int/ $>$.

DeJong, T.M., W. Tsuji, J.F. Doyle, and Y.L. Grossman. 1999. Comparative economic efficiency of four peach production systems in California. HortScience 34:73-78.

De la Guardia, M.D. and E. Alcántara. 2002. A comparison of ferric-chelate reductase and chlorophyll and growth ratios as indices of selection of quince, pear and olive genotypes under iron deficiency stress. Plant Soil 241:49-56.

Dell'Orto, M., L. Brancadoro, A. Scienza, and G. Zocchi. 2000. Use of biochemical parameters to select grapevine genotypes resistant to ironchlorosis. J. Plant Nutr. 23:1767-1775.

Ellsworth, J.W., V.D. Jolley, D.S. Nuland, and A.D. Blaylock. 1997. Screening for resistance to iron deficiency chlorosis in dry bean using iron reduction capacity. J. Plant Nutr. 20:14891502 .

Ellsworth, J.W., V.D. Jolley, D.S. Nuland, and A.D. Blaylock. 1998. Use of hydrogen release or a combination of hydrogen release and iron 
reduction for selecting iron-efficient dry bean and soybean cultivars. J. Plant Nutr. 21:26392651.

Felipe, A.J., J. Gómez-Aparisi, R. Socías, and M. Carrera. 1997. The almond $\times$ peach hybrid rootstocks breeding program at Zaragoza (Spain). Acta Hort. 451:259-262.

Fernández, C., J. Pinochet, D. Esmenjaud, G. Salesses, and A. Felipe. 1994. Resistance among new Prunus rootstocks and selections to root-knot nematodes from Spain and France. HortScience 29:1064-1067.

Fox, T.C., J.E. Shaff, M.A. Grusak, W.A. Norvell, Y. Chen, R.L. Chaney, and L.V. Kochian. 1996. Direct measurement of ${ }^{59} \mathrm{Fe}$-labeled $\mathrm{Fe}^{2+}$ influx in roots of pea using a chelator buffer system to control free $\mathrm{Fe}^{2+}$ in solution. Plant Physiol. 111:93-100.

Giorgi, M., F. Capocasa, J. Scalzo, G. Murri, M. Battino, and B. Mezzetti. 2005. The rootstock effects on plant adaptability, production, fruit quality, and nutrition in peach (cv. 'Suncrest'). Scientia Hort. 107:36-42.

Gogorcena, Y., J. Abadía, and A. Abadía. 2000. Induction of in vivo root ferric chelate reductase activity in fruit tree rootstock. J. Plant Nutr. 23:9-21.

Gogorcena, Y., J. Abadía, and A. Abadía. 2004. New technique for screening iron-efficient genotypes in peach rootstocks: Elicitation of root ferric chelate reductase by manipulation of external iron concentrations. J. Plant Nutr. 27:1701-1715.

Hell, R. and U.W. Stephan. 2003. Iron uptake, trafficking and homeostasis in plants. Planta 216:541-551.

Iglesias, I., R. Monserrat, J. Carbó, J. Bonany, and M. Casals. 2004. Evaluation of agronomical performance of several peach rootstocks in
Lleida and Girona (Catalonia, NE Spain). Acta Hort. 568:341-348.

Jiménez, S., Y. Gogorcena, C. Hèvin, A.D. Rombolà, and N. Ollat. 2007. Nitrogen nutrition influences some biochemical responses to iron deficiency in tolerant and sensitive genotypes of Vitis. Plant Soil 290:343-355.

Jolley, V.D., K.A. Cook, N.C. Hansen, and W.B. Stevens. 1996. Plant physiological responses for genotypic evaluation of iron efficiency in strategy I and strategy II plants: A review. J. Plant Nutr. 19:1241-1255.

Marino, G., S. Beghelli, A.D. Rombolà, and L. Cabrini. 2000. In vitro performance at high culture $\mathrm{pH}$ and in vivo responses to $\mathrm{Fe}$ deficiency of leaf-derived quince BA 29 (Cydonia oblonga) somaclones regenerated at variable medium pH. J. Hort. Sci. Biotechnol. 75:433-440.

Molassiotis, A., G. Tanou, G. Diamantidis, A. Patakas, and I. Therios. 2006. Effects of 4-month Fe deficiency exposure on Fe reduction mechanism, photosynthetic gas exchange, chlorophyll fluorescence and antioxidant defense in two peach rootstocks differing in $\mathrm{Fe}$ deficiency tolerance. J. Plant Physiol. 163: 176-185.

Moog, P.R. and W. Brüggemann. 1994. Iron reductase systems on the plant plasma membrane: A review. Plant Soil 165:241-260.

Moreno, M.A., M.C. Tabuenca, and R. Cambra. 1995. Adesoto 101, a plum rootstock for peaches and other stone fruit. HortScience 30:1314-1315.

Ollat, N., B. Laborde, M. Neveux, P. DiakouVerdin, C. Renaud, and A. Moing. 2003. Organic acid metabolism in roots of various grapevine (Vitis) rootstocks submitted to iron deficiency and bicarbonate nutrition. J. Plant Nutr. 26:2165-2176.
Reighard, G.L., D.R. Ouellette, and K.H. Brock. 2006. Growth and survival of 20 peach rootstocks and selections in South Carolina. Acta Hort. 713:269-273.

Romera, F.J., E. Alcántara, and M.D. De La Guardia. 1991a. Characterization of the tolerance to iron chlorosis in different peach rootstocks grown in nutrient solution. I. Effect of bicarbonate and phosphate. Plant Soil 130:115-119.

Romera, F.J., E. Alcántara, and M.D. De La Guardia. 1991b. Characterization of the tolerance to iron chlorosis in different peach rootstocks grown in nutrient solution. II. Iron-stress response mechanism. Plant Soil 130:121-125.

Santos, A. 2002. Selección de patrones de 'Prunus' resistentes a la clorosis férrica, pp. 116. Trabajo final de carrera Escuela Universitaria Politécnica La Almunia de Doña Godina. Zaragoza, Spain.

Sanz, M., J. Cavero, and J. Abadía. 1992. Iron chlorosis in the Ebro river basin, Spain. J. Plant Nutr. 15:1971-1981.

Schmidt, W. 1999. Mechanisms and regulation of reduction-based iron uptake in plants. New Phytol. 141:1-26.

Shi, Y. and D.H. Byrne. 1995. Tolerance of Prunus rootstocks to potassium carbonate-induced chlorosis. J. Amer. Soc. Hort. Sci. 120:283-285.

Socías i Company, R., J. Gómez-Aparisi, and A.J. Felipe. 1995. A genetical approach to iron chlorosis in deciduous fruit trees, p. 167-174. In: J. Abadía (ed.). Iron nutrition in soils and plants. Kluwer Academic Publishers, Dordrecht, The Netherlands.

Tagliavini, M. and A.D. Rombolà. 2001. Iron deficiency and chlorosis in orchard and vineyard ecosystems. Eur. J. Agron. 15:71-92.

Yi, Y. and M.L. Guerinot. 1996. Genetic evidence that induction of root $\mathrm{Fe}$ (III) chelate reductase activity is necessary for iron uptake under iron deficiency. Plant J. 10:835-844. 